\title{
Clínica Fenomenológica: Do Método de Pesquisa para a Prática Psicoterapêutica
}

\author{
William Barbosa Gomes ${ }^{1}$ \\ Thiago Gomes de Castro \\ Universidade Federal do Rio Grande do Sul
}

\begin{abstract}
RESUMO - Por clínica fenomenológica define-se a influência do método de Husserl nos tratamentos psicológicos. A presente exposição aborda: (1) a filosofia do conceito de existência, definida como cuidado de si, e de método fenomenológico, definido como estudo da consciência; (2) as polêmicas transformações sofridas pelo método fenomenológico para a análise da existência; e (3) a extensão da análise da existência para a psicoterapia como clínica fenomenológica. O estudo contrasta descrições do processo terapêutico existencial entre 1958 e 2007. Quanto às evidências empíricas, a resistência tradicional ainda é presente, mas com certa abertura. Aliás, os resultados das pesquisas são favoráveis. Nessa história, o método fenomenológico vem perdendo foco e a análise existencial movendo-se para uma abordagem psicoterapêutica mais integrada.
\end{abstract}

Palavras-chave: clínica; fenomenologia; existência; método; história da psicologia.

\section{Phenomenological Clinic: From Research Method to the Psychotherapeutic Practice}

\begin{abstract}
Phenomenological clinic is defined as the influence of Husserl's method upon psychological treatments. This paper addresses: (1) the philosophy of the concept of existence, defined as taking care of oneself, and of the phenomenological method, defined as the study of consciousness; (2) the controversial transformations undergone by the phenomenological method to analyze the existence; and (3) the extension of the existential analysis to psychotherapy as phenomenological clinic. The study contrasts descriptions of the existential therapeutic process from 1958 to 2007. As for empirical evidences, the traditional resistance is still present, but with some opening. Moreover, research findings are favorable. The historical interpretation indicates that the phenomenological method is losing focus and the existential analysis is moving towards a more integrated psychotherapeutic approach.
\end{abstract}

Keywords: clinic; phenomenology; existence; method; history of psychology.

Usualmente, clínica fenomenológica é o termo utilizado pela prática médica para se referir à descrição cuidadosa $\mathrm{e}$ exaustiva de sintomas. São exemplos, desse uso, estudos recentes como Fenomenologia e anatomia de comportamentos anormais em afasia progressiva primária (Rohrer \& Warren, 2010) e Delírios, ilusões e alucinações em epilepsia (Elliott, Joyce \& Shorvon, 2009). Ambos são estudos psiquiátricos preocupados com a descrição empírica de sintomas. O termo clínica fenomenológica também aparece como nomeando um setor do Departamento de Psiquiatria da Columbia University College of Physicians and Surgeons, dedicado a atividades de pesquisa, ensino e serviços sobre diagnóstico, biometria e personalidade. Nesse sentido, o termo abrange várias modalidades de diagnóstico e descrições concernentes à severidade dos sintomas, aos impedimentos funcionais, à qualidade de vida, ao decurso da doença, às respostas diferenciais ao tratamento, e aos concomitantes genéticos. A clínica fenomenológica seria, portanto, uma descrição abrangente, incluindo pacientes e não pacientes, tendo como objetivo a compilação exaustiva de dados que permitam

1 Endereço para correspondência: Instituto de Psicologia, UFRGS. Rua Ramiro Barcelos, 2600/123. Porto Alegre, RS. CEP 90035-003. Email: gomesw@ufrgs.br. ampla compreensão da doença e da respectiva situabilidade. Por exemplo, o estudo da própria doença, sua manifestação, história e contexto.

Embora o termo fenomenologia seja comum à prática médica, trata-se na verdade de uma extensão do uso de verbete oriundo da filosofia alemã setecentista. O termo ganhará destaque no início do século XIX com as filosofias de William Hamilton (1791-1856) e de Georg W. Hegel (1770-1831). O primeiro defendia a necessidade da distinção entre conhecimento e crença (Tonner, 2009) ${ }^{2}$ e o segundo destacava a descrição histórico-racional da experiência que a consciência faz de si mesmo em seu desenvolvimento dialético (Hegel, 1807/1997).

Ambos os filósofos repercutiram, a seu modo, influências do idealismo kantiano, com a clássica distinção entre nômeno ou númeno (o real) e fenômeno (o percebido). No entanto, o termo fenomenologia é reconhecido por nomear o método desenvolvido por Edmund Husserl (1859-1938) para estudar a experiência consciente. Posteriormente, o método, com modificações, foi utilizado por Martin Heidegger (1889-

2 Nota histórica: Hamilton defende sua posição em seu tratado Lectures on Metaphysics and Logic, Vol 1, editado em 1856 por H. L. Mansel and J. Veitch, William Blackwood and Sons, Edinburgh (Tonner, 2009). 
1976) para a analítica da existência. Certamente, o exemplo pioneiro de fenomenologia clínica é o livro Psicopatologia Geral (1913/2000), de autoria de Karl Jaspers (1883-1969), no qual o autor descreve os fenômenos psíquicos anormais no modo como se apresentam à experiência consciente. Com essa iniciativa, Jaspers inaugurou a aplicação do método fenomenológico à clínica médica e estabeleceu uma nova ciência da psicopatologia (Rodrigues, 2005).

Neste artigo, o termo clínica fenomenológica será utilizado para caracterizar uma terceira via de compreensão e atendimento psicoterápico que se tornou conhecido por fenomenologia-existencial, com ramificações para uma grande variedade de teorias psicológicas humanistas. Nessa via, tem-se a conjunção de uma filosofia e de um método para o estudo da relação entre experiência e consciência, entendida como fluxo de vivências pré-reflexivas. As vivências procedem de um olhar interno que não colocam em dúvida a concretude da externalidade. O problema é que a relação se prejudica por perder de vista o sujeito, dada a interferências da agitação cotidiana, do artificialismo das tecnicalidades e dos olhares insidiosos para os objetos. Essa foi a leitura que filósofos e psiquiatras nos ofereceram do mundo em que viviam na primeira metade do século XX, incluindo a contingência ao sofrimento encarnado na forma da angústia e da doença mental. Uma decorrência foi o incremento do cuidado consigo mesmo, representado pelo interesse na análise da relação entre consciência e experiência, sendo a relação reinterpretada como existência. A outra, foi o olhar suspeito ao mundo e às suas tecnicalidades, representadas em sua mais elevada expressão pelas ciências da natureza. Tais ciências ocupavam-se de objetos, sem considerar as implicações intervenientes para os sujeitos.

A presente exposição contempla os seguintes aspectos associados ao conceito de clínica fenomenológica: (1) considerações sobre os diferentes significados do termo fenomenologia; (2) considerações históricas e metodológicas; (3) nascimento da clínica psicológica; (4) perspectiva fenomenológica na clínica psicológica; (5) características da clínica fenomenológico-existencial; (6) clínica fenomenológico-existencial no Brasil; (7) pensamento brasileiro sobre a clínica fenomenológico-existencial; (8) temas fenomenológicos em Psicologia: Teoria e Pesquisa; (9) clínica fenomenológica: as evidências; e (10) considerações finais.

\section{Fenomenologia}

O uso do termo fenomenologia requer alguns cuidados. O primeiro deles é para a raiz do verbete, isto é, fenômeno, do grego phainómenon que quer dizer tudo aquilo que é passível de ser posto à luz, tudo aquilo que resplandece, iluminando-se (Campos, 2007). Fenômeno é o que aparece à percepção. No entanto, o termo fenômeno serve a muitas ciências: fenômeno físico, fenômeno biológico, fenômeno social, fenômeno psicológico, e assim por diante. Há muito tempo atrás, o filósofo francês Paul Janet (1823-1899), seguidor de Hegel e de Victor Cousin (1792-1867) distinguiu fenômeno de fato de uma maneira muito instrutiva:
Fato é de algum modo um fenômeno parado, preciso, determinado, com contornos que se podem apreender e desenhar: implica uma espécie de fixidez e de estabilidade relativas. $O$ fenômeno é o fato em movimento, é a passagem de um fato a outro, é o fato que se transforma em instante a instante. (Janet, 1865, p. 56, tradução livre) ${ }^{3}$

A definição de fenômeno que se aplica à fenomenologia, isto é, ao discurso, à descrição e à interpretação é esse movimento, esse fluxo, essa passagem que vai constituir o tempo da experiência para a consciência.

O segundo cuidado é não confundir fenomenologia com fenomenismo, doutrina pela qual o único conhecimento possível é o da aparência, das imagens percebidas, sendo as coisas-em-si incognoscíveis. São exemplos, o empirismo radical de David Hume (1711-1776) e o idealismo de Immanuel Kant (1724-1804). As implicações possíveis dessas doutrinas são os solipsismos, para os quais existem apenas o eu e suas sensações, sendo os outros entes meras impressões sem existência própria. Em síntese, o interesse é pelo fenomenal, o que é apreensível em sua vivacidade pelos sentidos e pelo conjunto desses fenômenos que compõem as fenomenalidades (Lalande, 1996).

\section{Considerações Históricas e Metodológicas}

O espectro teórico da psicologia em meados do século $\mathrm{XX}$ foi caracterizado por três forças dominantes: a psicanálise, o behaviorismo e o humanismo. A fenomenologia foi incorporada ao humanismo, ficando o termo associado à experiência subjetiva. Na verdade, a fenomenologia se refere à subjetividade, que é o sujeito cognoscente, com o objetivo de saber como o sujeito exerce a capacitação para o conhecimento. $\mathrm{O}$ método fenomenológico foi proposto como recurso epistemológico básico para todas as ciências. A fenomenologia deveria ser a ciência das ciências por focalizar a tomada de conhecimento, seja ele noético, referente ao processo de conhecer, seja ele noemático, referente ao objeto conhecido (Ihde, 1977).

O movimento humanista do meado do século XX tomou o existencialismo como tema central e a fenomenologia como método. Abordagens terapêuticas preocupadas com as questões da existência foram denominadas de fenomenológicoexistenciais, sendo seus terapeutas simpáticos ao método fenomenológico. O movimento humanista existencial experimentou seu apogeu nos meados do século XX, alcançou grande visibilidade na década de 1950 , recuou um pouco e retornou em grande estilo no célebre 1968 francês. A seguir, entrou em crescente declínio com o aparecimento de outras novidades como o estruturalismo, pós-estruturalismo e suas decorrências midiáticas no final do século XX, principalmente em França. Uma lista de pensadores críticos ao existencialismo incluiria os estruturalistas Claude Lévi-Strauss (1909-2009), Louis Althusser (1918-1990), Jacques Lacan

3 Un fail est en quelque sorte un phénomène arrêté, précis, déterminé, ayant des contours que l'on peut saisir et dessiner: il implique une sorte de fixité et de stabilities relatives. Le phénoméne, c'est le fait en mouvement, c'est le passage d'un fait à un autre, c'est le fait qui si trnasforme d'instant en instant. 
(1901-1981), e principalmente Michel Foucault (1926-1984) (Huisman, 1997/2001). No entanto, os ideais existencialistas continuam presentes nas terapias humanísticas, principalmente nas fenomenológico-existenciais, como atestam a publicação de livros e revistas, o surgimento de sociedades e a abertura de centros de formação, acadêmicos e profissionais.

A obra mais eloquente sobre psicologia fenomenológica é o clássico Phenomenology in Psychology and Psychiatry, de Spiegelberg (1972). Uma obra muito referida no Brasil é Existential-Phenomenological Perspectives in Psychology, organizada por Valle e Halling (1989). Contudo, a obra de referência brasileira por excelência é o texto sobre psicologia fenomenológica de Forghieri (1993). Para uma revisão histórica e conceitual, consulte-se o artigo A Brief History of Existential-Phenomenological Psychiatry and Psychotherapy, de Halling e Nill (1995). As revisões continuam, como ilustram os trabalhos recentes de Cooper (2009), que retorna aos fundamentos da psicoterapia existencial para focalizar os desenvolvimentos do existencialismo radical no Reino Unido, sob a influência da antipsiquiatria de R. D. Laing (1927-1989) e do handbook de Hoffman, Yang, Kaklauskas e Chan (2009), com a defesa da relevância da psicologia existencial para o mundo contemporâneo. Uma característica desses trabalhos é a combinação de dados biográficos dos psicoterapeutas com a definição dos conceitos básicos. Assim, o presente trabalho focalizará o argumento fenomenológico na prática clínica, considerando que dados biográficos são hoje de fácil acesso (consultar sistemas de buscas na $w e b$ ) e que os conceitos básicos já foram por demais definidos nas obras mencionadas. Adianta-se que se a fenomenologia serviu de inspiração para os psicoterapeutas fundadores, hoje se apresenta distanciada ou apenas implícita na prática clínica. Por restrições de escopo e espaço não serão apreciados tratamentos psicológicos convergentes como a Logoterapia, a Abordagem Centrada na Pessoa e a Gestalt Terapia. A primeira foi identificada desde o início como uma terapia existencial (Frankl, 1946/1973), a segunda foi reconhecida por Spiegelberg (1972) como o tratamento psicológico originado nos EUA com maior proximidade à fenomenologia, e a terceira tem mostrado interesse crescente na pesquisa fenomenológica (ver Tavares \& Andrade, 2009).

\section{Nascimento da Clínica Psicológica}

O termo clínica psicológica foi utilizado pela primeira vez por Lightner Witmer (1867-1956) em 1907 (Hilgard, 1987). Um termo muito próximo foi anteriormente utilizado no Brasil pelo psiquiatra Odilon Goulart, no título de sua tese de doutorado, Estudo Psicoclínico da Afasia, defendida na Faculdade de Medicina do Rio de Janeiro, em 1891 (Lourenço Filho, 1955).

A clínica psicológica é historicamente associada à psicoterapia. Psicoterapia pode ser definida como a arte e a ciência que se dedica ao alívio do sofrimento humano, decorrente de conflitos e desordens emocionais. É arte por implicar no desempenho de procedimentos técnicos mediados por competências tácitas. É ciência por sustentar-se na evidência dos próprios resultados, conforme alertado por Freud (193840/1998). A psicoterapia é um processo comunicacional no qual uma pessoa (o profissional) compreende e intervém em outra pessoa (paciente/cliente) que busca ser ouvida ou tratada. Esse atendimento pode ser individual ou grupal, para casais ou para famílias, podendo assumir práticas ampliadas como atendimento à comunidade, nas mais diversas combinações sociais e culturais. Pode valer-se de expressividade corporal como dança, desenhos, mímica e drama. As manifestações expressivas, em geral, são posteriormente encaminhadas para apreciação verbal avaliativa no sentido vivencial, cognitivo e comportamental.

A prática psicoterápica assenta-se em dois fundamentos: (1) foco na relação interpessoal na situação de tratamento; e (2) foco em práticas reeducativas. O primeiro fundamento remete à psicanálise (Luborsky, O'Reilly-Landry \& Arlow, 2010) e o segundo, à psicoterapia adleriana (Mosak \& Maniacci, 2010). Desse modo, faz-se justiça a essas duas grandes contribuições científicas aos tratamentos psicológicos.

A história da psicanálise é bastante conhecida e de fácil acesso. Mesmo assim, convém pontuar episódios que culminaram com a proposição da técnica. Entre 1880-82, o médico austríaco Josef Breuer (1842-1925) descobre que instabilidades emocionais, acompanhadas de impedimentos físicos, poderiam ser tratadas por indução hipnótica. Ele observou que a evocação de cenas patogênicas da infância estava relacionada à remissão dos sintomas. Dez anos depois, ele volta ao tema em colaboração com o então jovem médico Sigmund Freud (1856-1939) e juntos publicam os estudos sobre a histeria (Breuer \& Freud, 1895/1987). Tem-se, então, o modelo metodológico empírico clássico, no qual, um caso (e.g., Anna O) é associado a um resultado (remissão dos sintomas), por resposta a uma provável regra (indução hipnótica e conversação). Os conteúdos dos três passos foram revistos, mas foram suficientes em seus primórdios para apontar características especiais da relação entre terapeuta e paciente, que mais adiante foram definidas como transferência e contratransferência. Esse modelo relacional será de suma importância para o movimento psicoterapêutico e, particularmente, para a clínica fenomenológica. Com base nesse fundamento, pode-se afirmar que o tratamento só começa seus efeitos quando a relação se converte em foco das considerações terapêuticas.

Moss (1989) sintetizou o tratamento psicanalítico como se caracterizando por oferecer ao paciente uma oportunidade de expressar verbalmente o que estiver sentindo e pensando, por meio de associações livres. O tratamento tem em vista: (1) trazer conflitos e impulsos inconscientes para a consciência; (2) transformar sentimentos aparentemente desconexos ou estranhamente desejosos e reconhecidos com constrangimento, em atitudes e ações desejadas e assumidas; (3) identificar, durante o processo analítico, experiências traumáticas vividas nos primeiros anos de vida que possam contribuir para o esclarecimento das condições atuais de vida. A expressão verbal de sentimentos e pensamentos é mediada, fundamentalmente, pela clarificação, confrontação e interpretação. Sem dúvida, essa também foi a formação básica que norteou os primeiros psicoterapeutas existenciais.

Durante as primeiras décadas do século XX, as ideias de Adler competiam em igualdade com as de Freud. No entanto, não alcançaram a mesma visibilidade da psicanálise. Não bastasse isso, a grande influência que exerceram nas várias 
psicoterapias é pouco reconhecida. Não seria errôneo afirmar que os muitos sistemas psicoterapêuticos, ou assentam-se no fundamento relacional freudiano ou no fundamento reeducativo adleriano. Exceções seriam para grupos recentes com raízes no pensamento oriental ou grupos minoritários místicos e alternativos. A influência adleriana, mesmo que não mencionada, é cada vez mais forte nas psicoterapias existenciais.

A clínica fenomenológica vai nascer nas cercanias desses dois grandes fundamentos, a relação e a reeducação, com forte influência psicanalítica. Os grandes praticantes da clínica fenomenológica foram treinados em psicanálise e entendiam que a prática exercida era também uma psicanálise. Ainda hoje é comum psicoterapeutas fenomenológicoexistenciais se apresentarem como psicanalistas. Spinelli (2007), por exemplo, critica reconhecidos representantes da análise existencial, por atuarem muito próximos do enquadre psicanalítico. O autor cita Yalom (1980), na verdade um dos nomes mais evidentes na tradição nas últimas três décadas, e Deurzen-Smith (1997), fundadora da Society for Existential Analysis em Londres.

\section{Perspectiva Fenomenológica na Clínica Psicológica}

Ludwig Binswanger (1881-1966), em um texto sobre os progressos da psicoterapia (Binswanger, 1958), apresentou a análise existencial (Daseinsanalyse) como um método de pesquisa fenomenológico psiquiátrico. Essa breve referência aponta de imediato para as conexões entre análise existencial e método fenomenológico. Esclarece-se, assim, a origem da vertente psicoterápica que viria a ser conhecida, entre outras denominações, como fenomenológico-existencial, psicoterapia existencial ou mesmo psicoterapia humanísticoexistencial. Binswanger justificou a menção ao método por entender que desde Freud e Carl Jung (1875-1961), a psicoterapia era um projeto de pesquisa em andamento, com poucos avanços. O método fenomenológico ganha importância diante das limitações das psicoterapias de cumprir sua finalidade em aliviar o sofrimento dos pacientes. As psicoterapias não respondiam bem às diversas modalidades de aflições mentais. Os dois conceitos, identificados como novos recursos ao tratamento, procediam de tradições distintas, embora não tão distantes uma da outra: o problema da relação entre sofrimento e existência, e da relação entre psicoterapia e método. A seguir, cabe o exame de cada uma dessas noções, a saber, existência e método, para depois rever como estes se encontram na vasta e dispersa corrente das psicoterapias existenciais.

\section{Filosofia existencial}

Em sua breve e esclarecedora história do existencialismo, Huisman (1997/2001) define existência como uma crise não resolvida e aparentemente sem solução entre a apreensão dos propósitos e dos questionamentos que se assume diante da vida. Enfrenta-se a crise da existência numa redefinição de religiosidade ou na negação dessa religiosidade. O impasse está ou no silêncio de Deus ou na efemeridade dos valores. A questão é o que fazer diante desse vazio inconfortável e perturbador. Huisman nos lembra que esse desconforto atravessou séculos. Esteve com Sócrates (469-399, a.C.), na filosofia do vivido, do retorno a si, do cuidado, do conhecer a si mesmo. Esteve com Descartes (1596-1650), no apelo à transcendência e à emergência de uma consciência livre. Esteve com Pascal (1623-1662), no esforço de reconduzir o homem à meditação sobre a condição da própria vida diante da grandeza do universo, das agruras do cotidiano e da iminência da morte.

Com efeito, a história do pensamento filosófico debatese, desde os seus primórdios, com dois pólos opostos: (1) a proposição objetiva de um sistema metafísico a partir das ideias de homem (alma), de mundo e de Deus; e (2) a busca de uma compreensão para o homem, para o mundo e para Deus que viesse da interioridade, do sentimento, da experiência vivida, da subjetividade. Esse debate ganhou contornos de uma disputa entre a lógica da razão, a racionalidade e a estética do intuitivo, o romantismo (Löwy \& Sayre, 1992/1995). Com a racionalidade, articulavam-se argumentos lógicos que sustentariam a filosofia da idade moderna. Com a intuição, buscava-se compreender a irracionalidade humana, presenciada em conflitos, guerras, confrontos e mesmo nas leis; ou usufruída na estética das artes, da literatura e das narrativas históricas. O desconforto insuportável diante da incoerência humana entre razão e ética ganhou contornos estridentes e encaminhamentos distintos no pensamento de Søren Kierkegaard (1813-1855) e Friedrich Nietzsche (1844-1900).

Kierkegaard (1843/2008) apercebe-se em pleno vazio de vida, em parte oriundo da hipocrisia religiosa de sua comunidade, em parte resultante da formalidade racional rígida e artificial dos sistemas filosóficos, e em parte com a renúncia ao casamento para não se tornar um funcionário conjugal. Em sua busca por uma vida autêntica, coerente e consistente diante da necessidade da fé cristã, ele criticava o formalismo religioso, a rotina estéril de pedir perdão dos pecados e, ao mesmo tempo, viver tranquilamente em pecado. Daí as perguntas, como se tornar cristão ou como exercitar a fé. A fé parecia-lhe a única saída para a existência, mesmo assim seria uma existência aflita, pois a fé em si é um mistério. O sofrimento exigia uma experiência real e não simplesmente o conhecimento. Por isso, a rejeição tanto ao formalismo totalizante do idealismo absoluto de Hegel, que incluía a existência humana, quanto a certeza da ética de Kant, para a qual a escolha já estava decidida em favor do bem universal. Para Kierkegaard, essa abstração formal era vazia, distanciada do sofrimento da existência. A saída estava na fé, que não se reivindica, mas se experimenta. No celebrado Ou...Ou... (A Alternativa), Kierkegaard (1843/1959) descreve o aprendizado da vida em três estágios, nos quais a falta de sentido do imediatismo (esfera estética) pode levar ao desespero e à procura de alternativas (esfera ética) que, se bem encaminhadas, levariam para longe do imediato e do cinismo em direção à entrega a Deus (esfera religiosa). Contudo, a crise tem que continuar para que não se retorne ao vazio. Essa crise, para Kierkegaard, é a manutenção da incerteza no lugar da verdade, isto é, a dúvida da fé, para continuar com fé, pois sem Deus o homem perde a sua significação. 
O caminho escolhido por Nietzsche $(1881 / 2004)$ será outro. Seu pensamento reflete o estado de desenvolvimento da filosofia e da ciência em seu tempo, quando o homem não era mais entendido como uma criatura de Deus e assim lançado ao mundo e à sua própria sorte. Ao contrário de Kierkegaard, desloca a fé em Deus para a fé no homem, e coloca as obras acima da fé. Para Nietzsche, o dilema humano estaria situado no embate entre a inteligência e a ação. A inteligência estaria a serviço da ação, pronta a orientá-la, a dirigi-la, a efetuar escolhas, pois o sentido da vida estava na ação, nos atos do dia a dia. Na ausência de Deus, os valores morais perdem sentido, cabendo à inteligência substituir os valores pela responsabilidade das próprias escolhas. Contudo, a inteligência era levada pelos costumes gerais a tomar cuidados genéricos que sufocavam o cuidado a si e as próprias ações. O que restava então? A rejeição dos valores morais abria o caminho para a liberdade, mesmo que acompanhada pela angústia de ter que tomar decisões por si mesmo.

Enfim, seja com Deus ou sem Deus, Kierkegaard $(1843 / 1959)$ e Nietzsche (1881/2004) falavam de um ser humano que estava diante da responsabilidade de fazer escolhas, tomar decisões e sofrer as consequências. Esses dois filósofos ou contrafilósofos delinearam com força e dramaticidade o tema da existência, que haveria de retornar com todo o ímpeto entre as duas grandes guerras mundiais do século XX. Tendo descrito o problema da existência, cabe agora levantar a questão do método.

\section{Método fenomenológico}

A relação entre o método fenomenológico proposto por Husserl e o existencialismo é polêmica. Nos meados do século XX, a posição dominante dos intérpretes de Husserl apontava para uma abstração idealista da redução transcendental incompatível com a concretude da existência (Kockelmans, 1967). No entanto, avaliações das últimas décadas vão à outra direção, identificando na mesma redução transcendental uma explícita declaração pró-existencialismo (Huisman, 1997/2001). Nossa próxima tarefa é recuperar informações básicas do método fenomenológico para, então, tomar uma posição nessa polêmica entre fenomenologia e existencialismo.

Husserl (1929/1968) definiu a fenomenologia como um método filosófico descritivo: (1) capaz de circunscrever uma psicologia a priori que fundamentaria a psicologia empírica; e (2) capaz de, como filosofia universal, proceder à revisão metodológica de todas as ciências. A definição de Husserl não deixa dúvidas e nos coloca diante de uma clara posição racional frente à psicologia empírica e à filosofia (ver Ferraz, 2004). O método fenomenológico apresenta-se como importante não só para a psicologia, mas para todas as ciências. Daí a aparente incompatibilidade com a subjetividade intuitiva do existencialismo. O problema do método fenomenológico não seria, portanto, a clarificação da subjetividade, mas a depuração da racionalidade na busca do conhecimento.

O método fenomenológico (Husserl, 1901/2007) aplicase à relação entre consciência e experiência. A consciência é definida como uma estrutura apta para tomar conhecimento do que se apresenta na experiência. O conhecimento decor- re desse movimento da consciência para a experiência. Na experiência está o mundo com a vivacidade dos seus muitos objetos, pois sem experiência não há consciência. A consciência, por sua vez, é permeada por uma história de vida, por crenças e convicções remotas e atuais, e por projetos de maior ou menor clareza sobre o futuro. Essa rica estrutura, constituída pela correlação intencional entre consciência e experiência, uma correlação que define a experiência consciente e a subjetividade (sujeito cognoscente), será prejudicada na ausência de reflexão. O papel da reflexão é clarificar a experiência para a consciência, e a consciência para ela mesma. A possibilidade dessa clarificação está no método fenomenológico por meio de suas reduções. Por isso, o método fenomenológico é a arte sistemática da reflexão.

As reduções (Husserl, 1913/2006) embasam a análise capaz de elucidar a relação entre experiência e consciência, e entre consciência e consciência. O objetivo é encontrar a abertura para o novo que está escondido na diversidade da experiência e nas sombras da consciência. As reduções são necessárias para implodir a unidade do mundo e a unidade da consciência, e com a implosão estabelecer um elo entre elas. $\mathrm{O}$ mundo se refere à consciência e a consciência só vem a se conhecer se conseguir desvendar a sua estrutura transcendental que é o arcabouço da subjetividade, o puro Ego. Em outras palavras, a plataforma inicial do método implica em uma estrutura Ego-mundo, na qual o mundo se refere ao Ego. $\mathrm{Na}$ naturalidade das relações, o Ego se percebe no mundo estando acima e contra outros egos, na posição privilegiada de centro intencional, absoluto no seu poder ou perdido nas suas fraquezas. As reduções são os passos operacionais da análise que inicia e segue com os exercícios já muito conhecidos da epoché fenomenológica. Um exercício que suspende ou que rebaixa, que focaliza ou que encobre as muitas aparências que os objetos assumem (análise noemática) e as muitas maneiras de se refletir sobre eles (análise noética). A suspensão é na verdade um giro imaginário e criativo sobre os constituintes dos objetos, dos seus contextos, das suas implicações para o mundo e para o Ego. Em princípio, a epoché pode ser considerada estranha, irreal e até impossível de se realizar, mas é um recurso poderoso para a condução do pensamento sistêmico e sistemático (Gomes, 2007). A epoché é também importante para a descoberta de soluções inesperadas. Para Husserl, a ficção é uma propriedade fundamental para a fenomenologia e para todas as ciências eidéticas (Casey, 1977).

Vencida a primeira redução, vai-se adiante para dar início à redução transcendental. Esta confronta as bases do sujeito cognoscente, penetrando nas entranhas da subjetividade de onde se originam os valores desenvolvidos pelas exposições externas e idiossincrasias internas. Ao excluir, pelas suspensões, a mundanidade da experiência, espera-se encontrar a subjetividade com as suas excentricidades que determinam as escolhas. Contudo, a redução transcendental não é um movimento de si para si, mas uma depuração de si para o retorno à experiência. É o modo de se reaver a objetividade (Husserl, 1913/2006).

A contribuição que Husserl traz à filosofia e à ciência é enorme. Ele redefine a consciência, que deixa de ser entendida como substância ou conteúdo, passando a ser descrita como fluxo, tensão, agente, abertura ao mundo (Husserl, 1913/2006). Desse modo, o retorno à experiência é pré- 
reflexivo e tensional, dissolvendo a dicotomia sujeito-objeto, não para desfazê-la, mas para reconstruí-la. É nesse retorno que se evidencia a intersubjetividade, a relação interpessoal, o convívio com o social onde se encontram os outros e as suas consciências. A redução transcendental não é um aprisionamento etéreo, mas uma oportunidade dada à subjetividade para abrir-se, reflexivamente, à relação com o outro.

No entanto, a proximidade entre fenomenologia e existencialismo, e o distanciamento entre Husserl e Heidegger parece ter ocorrido em torno das reduções e das suspensões. A propósito, suspende-se aqui qualquer consideração sobre as interferências políticas da época nas atitudes e posições de Heidegger a favor do nazismo e nas implicações de tais posições em sua relação pessoal com Husserl (ver Farías, 1989). O interesse é a mudança do foco fenomenológico da relação entre consciência e experiência, para a relação do ser humano consigo mesmo, essa entidade que será chamada de Ser-aí. Esse Ser-aí que se coloca como questão para a tal entidade que somos nós mesmos. Se, para Husserl (1901/2007), a experiência com a sua mundaneidade constitui a consciência, pois a consciência é sempre consciência de algo, para Heidegger (1927/1989) essa experiência aparecerá engrandecida como a existência que se coloca ao Ser-aí. A nova análise fenomenológica deve partir da existência humana, do Ser-aí, tal como se dá imediatamente à consciência.

Para Kockelmans (1967), Heidegger parte de uma posição comum a Husserl, de que cada tipo de Ser se dá e se manifesta ao seu próprio modo. Os dois também concordam com a necessidade de se redefinir o conceito de mundo natural. No entanto, Heidegger (1927/1989), embora utilize a descrição fenomenológica e o retorno às profundezas da subjetividade, não aceita as reduções husserlianas. A intencionalidade é então aquilo que se mostra a si mesmo em si mesmo, e não mais a direcionalidade da consciência para o objeto. Para Heidegger, as sucessivas reduções de Husserl levam a um idealismo no qual o sujeito se separa do mundo, quando sujeito e mundo são inseparáveis. Essa inseparabilidade caracterizará o Ser e a sua concretude existencial, isto é, um ser em situação no espaço, no tempo (contemporaneidade de passado, presente e futuro) e nas relações interpessoais. As reduções são substituídas por outro recurso metodológico, a hermenêutica, para compreender os humanos em situalidade.

Em Ser e Tempo, Heidegger (1927/1989) apresenta uma análise fenomenológica da existência na qual descreve a vida cotidiana do homem, considerada inautêntica, em três movimentos: a facticidade, a existencialidade e a ruína. A facticidade é existência na imersão involuntária no mundo, desde que as pessoas chegam ao mundo independente de escolha. A existencialidade é o apoderamento crítico dos modos de sua relação com o mundo, tentando superar seus limites, buscando ser o que não é. A ruína seria o afastamento de si em favor das preocupações cotidianas, levando a um esfriamento em relação a si mesmo. As relações dessa descrição do que se passa nas sessões psicoterapêuticas são óbvias e a associação entre a inautenticidade e as aflições mentais é consideravelmente forte. Nessa mesma época, um expressivo número de psiquiatras começava a preocupar-se com outra conjuntura germinadoura da doença mental que não as apontadas pela teoria freudiana.

\section{Características da Clínica Fenomenológico-Existencial}

O interesse pelas questões existenciais atraiu filósofos, psiquiatras e psicanalistas no período entre as duas grandes guerras mundiais e, principalmente, no pós-guerra. No mesmo ano que Heidegger (1927/1989) publicava Ser e Tempo, Gabriel Marcel (1889-1973) lançava o Journal Métaphysique, com notas filosóficas sobre temas existenciais, com especial atenção à relação do corpo com os objetos, e um entendimento que as sensações forneciam formas e não mensagens. Na década de 1930, aparecem os trabalhos de Eugéne Minkowski (1875-1972) sobre tempo vivido, Jaspers sobre filosofia da existência, e Erwin Straus (18911975) sobre o mundo primário das sensações. Na década de 1940, o interesse existencial é dominante com trabalhos publicados por Maurice Merleau-Ponty (1908-1961), com a Fenomenologia da Percepção (1945/1999), e Jean-Paul Sartre (1905-1980), com o Ser e o Nada (1943/2005), e, sobretudo, com as proposições de psicoterapia fenomenológico-existencial presentes nos trabalhos de Binswanger e Viktor Frankl (1905-1997). Na década seguinte, Medard Boss (1903-1990) escreve o seu primeiro livro sobre sonhos (1953/1958), e May, Angel e Ellenberg (1958) organizam Existence: A New Dimension in Psychiatry and Psychopatology, a obra que irá levar essas ideias e propostas para a América do Norte.

Entre as obras associadas com a análise existencial, a de Binswanger, The Existencial Analysis School of Thought (1958), tem sido a principal referência quanto às orientações gerais que caracterizam a prática da psicoterapia analíticoexistencial, conforme apresentadas a seguir.

A psicoterapia existencial investiga a história de vida de um paciente, como em qualquer outro método terapêutico. Contudo, não busca explicar a história de vida e suas idiossincrasias patológicas. Ao contrário, compreende esta história de vida como modificações da estrutura total do serno-mundo dos pacientes.

Essa modalidade de terapia não mostra apenas onde, quando e até que ponto o paciente falhou em realizar a totalidade de sua humanidade, mas tenta fazê-lo experienciar isso o mais radicalmente possível. O objetivo será alcançado o quanto mais rápido o terapeuta explorar, não as estruturas temporais, mas as estruturas espaciais do mundo de significação de um paciente.

O lugar do terapeuta no setting é o plano de uma existência em comum, sendo o paciente um parceiro existencial. A psicoterapia será um encontro, um ser-com. O que Freud (Binswanger, 1958) chamou de transferência será entendido como um tipo de encontro baseado em presença genuína, em um presente que é a continuidade do passado e que visa as possibilidades do futuro.

A posição da análise existencial em relação aos sonhos não é explicativa. Entende os sonhos como uma forma específica de existência. Nos sonhos, o que se observa é o homem total, portanto, a função da terapia deve ser abrir novas possibilidades estruturais para esses processos existenciais alterados.

A análise existencial não pode dispensar os métodos tradicionais terapêuticos, mas deve usá-los apenas com o pro- 
pósito de favorecer a abertura ao homem para a compreensão da estrutura existencial humana. $\mathrm{O}$ uso dos métodos deve permitir, em última instância, o exercício da liberdade para que o indivíduo utilize suas próprias capacidades existenciais.

De modo semelhante a Binswanger, o psicólogo norteamericano Rollo May descreveu seis implicações terapêuticas consequentes de uma visão existencial na prática clínica (May, 1958). A primeira sugere que a variabilidade de técnicas entre terapeutas existenciais converge quanto à prevalência da compreensão na determinação do uso da técnica, e não ao contrário. Ou seja, não é a compreensão que se orienta pela técnica, mas a técnica que acompanha a compreensão existencial do terapeuta. As técnicas existenciais devem ser versáteis e flexíveis, variando de paciente para paciente e de uma fase a outra no tratamento com o mesmo paciente. A segunda é que o dinamismo psicológico interpretável deve assumir sempre um sentido a partir da situação existencial imediata de um paciente. O centro desse dinamismo psíquico deve ser a possibilidade inimputável de exercício da liberdade.

A terceira implicação indica que a ênfase de uma terapia existencial reside na presença. Isso é, que a relação entre paciente e terapeuta contemple a compreensão e experiência do terapeuta o mais próximo possível do ser do paciente. Uma experiência participativa do terapeuta no campo de relações do paciente. May (1958) destaca que presença não deve ser confundida com uma atitude sentimental, pois indica o sentido compreensivo da atitude fenomenológica na relação, substituindo a posição de análise por explicação. A quarta refere-se às formas de comportamento que destroem a presença. A confrontação entre duas pessoas pode ser profundamente criadora de ansiedade. Nesse sentido, a visão técnica de outra pessoa pode ser a forma terapêutica mais utilizada para a redução de ansiedade. Contudo, a técnica não deve ser uma forma para bloquear a presença.

A quinta implicação remete-se ao objetivo do processo terapêutico. $\mathrm{O}$ foco de uma terapia existencial é de que o paciente experimente sua existência como real, o que significa tornar-se consciente de suas potencialidades e estar apto para agir com base nelas. A sexta e última implicação indicada por May (1958) refere-se à importância do compromisso existencial do paciente. O psicólogo afirma que a decisão pela mudança precede o conhecimento, o que implica afirmar que conhecer-se e aumentar o numero de insights sobre si não possui valor sem que se tome uma orientação prévia decisiva para a vida.

Para Moss (1989), o processo temporal terapêutico, orientado por princípios fenomenológicos e experienciais, caracteriza-se por três fases. Na fase de abertura, o terapeuta tem o desafio de sintonizar, de se unir e de acompanhar o fluxo de experiência do paciente. Na fase intermediária, terapeuta e paciente seguem unidos para um desafio duplo, qual seja aceitar a vida e o mundo de cada um enquanto se apresentam e se aprofundam na relação. Nesse momento, importa o entendimento da realidade alheia como o produto das escolhas de cada um, mais do que todos os fatos contingenciais e acidentais. Na ultima fase da temporalidade terapêutica, paciente e terapeuta enfrentam as limitações do tempo e da situação existencial, considerados por Moss como centrais na psicoterapia e na vida. Ao aceitar tais limitações, atribui-se ao tempo terapêutico grande seriedade e valor, impulsionando a criatividade dos parceiros terapêuticos para lidar com as contingências existenciais.

Sem muitas alterações nas linhas gerais dos seus antecessores, Deurzen (2007) relata que os objetivos do processo terapêutico existencial devem permitir: (1) que as pessoas tomem posse de sua situação, de seus valores e de suas crenças; (2) negociem o arranjo entre crises do passado, presente e futuro; (3) busquem maior autoconfiança; (4) ampliem suas perspectivas em si mesmo e no mundo à sua volta; (5) encontrem clareza sobre o seu sentido de vida e como podem aprender do passado para criar algo no presente; (6) valorizem um sentido pelo que viver; (7) entendam a si mesmos e aos outros da melhor forma e achem meios para com eficiência se comunicar e estar com os outros; e (8) produzam sentido a partir dos paradoxos, conflitos e dilemas de sua existência.

Nesse espectro, Deurzen (2007) entende que o termo autenticidade, amplamente difundido como síntese desejável para o resultado eficaz da psicoterapia existencial, pode levar à desentendimentos. Para a autora, uma compreensão equivocada de autenticidade conduz à crença de que existe um estado ideal e real de self, enquanto para a visão existencial este self é relação e processo, não um resultado que sugira uma entidade ou substância ideal. Em síntese, autenticidade como meta terapêutica deve ser entendida enquanto processo gradual de ampliação da autocompreensão da própria condição humana.

Textos que apresentam a tradição fenomenológico-existencial (e.g., Halling \& Nill, 1995; Moss, 1989) ressaltam que essa tradição não teve nas suas origens e na sua história um nome que agregasse as correntes e servisse de referência para disputa nas várias interpretações teóricas. A abordagem foi desenvolvida por vários autores em diferentes países e os seguidores sempre foram livres para conduzirem a teoria e a prática conforme entendimento pessoal. Mesmo assim, comparando a descrição do processo terapêutico desses quatro autores encontra-se uma impressionante convergência genérica entre a compreensão da terapia e a prática.

A convergência genérica acentua-se quando se examina o caso clínico apresentado por Mendelowitz e Schneider (2008), no qual uma mulher com severa insatisfação com a sua vida e com o seu corpo, e sem histórico de doenças mentais, submete-se a uma psicoterapia existencial. Três momentos dessa descrição merecem atenção: (1) terapeuta encoraja paciente a expressar sua indignação e raiva com a sua situação atual e, ao mesmo tempo, busca valorizar suas qualidades e potencialidades; (2) terapeuta articula um tratamento em cooperação com outro serviço para perda de peso; (3) paciente insurge-se contra o terapeuta, indignada com o tipo de relação estabelecida. Note-se que o primeiro momento é compatível com as características indicadas pelos autores mencionados acima, $o$ segundo traz uma intervenção educativa do terapeuta alinhada com a tradição adleriana e o terceiro evidencia a importância da relação interpessoal para o tratamento. $\mathrm{O}$ enfrentamento da paciente ao terapeuta serviu para colocar a relação em foco e, efetivamente, dar início de fato ao tratamento. De qualquer modo, os terapeutas existenciais parecem nos apontar para um projeto básico de tratamento, onde o terapeuta reeduca e discute a relação, alcançando muito apropriadamente $o$ primeiro ponto levantado por Binswanger (1958). 


\section{Clínica Fenomenológico-Existencial no Brasil}

De acordo com Silva Neto (2004), a fenomenologia chega ao Brasil nos anos da década de 1930. Waclav Radecki (18871953) já mencionava Husserl no seu Tratado de Psicología. Conforme a versão em espanhol:

En este sentido, la función de discriminación, puede también, ser considerada como función de delimitación subjetiva de lo focal. El mecanismo de discriminación aqui analizado, corresponde, desde cierto pundo de vista, a las funciones de abstracción en el sentido dado a este término por Husserl, Külpe y Titchener e al processo de apercepción de Wundt. (Radecki, 1933, p. 61)

Nilton Campos (1889-1963), membro do mesmo laboratório de psicopatologia de Radecki, no Rio de Janeiro, foi também influenciado pela fenomenologia. Em 1930, publicou Psicologia da Vida Afetiva (Campos, 1930), no qual, inspirado pelas ideias da Escola de Würzbourg, conduzida por seguidores de Franz Brentano (1838-1917), entende o procedimento de observação fenomenológica como a perspectiva mais apropriada para o desenvolvimento da psicologia contemporânea. Em 1951, Campos lança o livro O Método Fenomenológico na Psicologia, oriundo do seu trabalho de doutorado na Universidade do Brasil, atual Universidade Federal do Rio de Janeiro, onde aponta a origem comum dos conceitos fundamentais do método fenomenológico e da psicologia da Gestalt, além de sua relação com a psicologia empírica de Brentano (Silva Neto, 2004).

Silva Neto (2004) aponta que, em meados da década de 1950, deu-se a associação entre fenomenologia e existencialismo nos círculos acadêmicos brasileiros. No campo da psicoterapia, o autor relata como importante capítulo desse encontro o trabalho apresentado por Enzo Azzi (1921-1985), em 1954, sobre o tema da atitude filosófico-científica da pesquisa fenomenológica em psicopatologia. Azzi considerava Heidegger o maior influenciador do campo e Binswanger, o principal elaborador. Conforme Silva Neto, Azzi destaca uma importante distinção entre a Analítica Existencial, entendida como "classificação filosófico-fenomenológica da estrutura a priori transcendental do Dasein" (p. 69), e a Análise Existencial, que significa a análise empírico-fenomenológica dos modos e formas concretas do Dasein.

Ainda de acordo com Silva Neto (2004), o desenvolvimento mais expressivo e intenso das vertentes de psicopatologia e psicoterapia associadas à fenomenologia no Brasil ocorreu nas décadas de 1960 e 1970 . Muito desse desenvolvimento justificado pelo estímulo concedido por psicólogos alinhados ao Aconselhamento Psicológico Centrado na Pessoa ou Psicologia Humanista. Historicamente, desde o emparelhamento com as vertentes humanistas, a fenomenologia e o existencialismo passaram a ser impulsionados e identificados com o humanismo no Brasil. Sobre este aspecto, Penna (1985) explicita a distinção entre psicologia fenomenológica e psicologia existencial, embora encontre um denominador comum de abordagens humanista entre ambas.

Gomes, Holanda e Gauer (2004) corroboram a tese de associação histórica entre humanismo, fenomenologia e existencialismo na psicologia brasileira. Segundo os autores, nesse campo, quando se referindo à psicoterapia, fala-se em existencialismo ou em fenomenologia existencial, sendo a fenomenologia base reflexiva para a análise da existência. No entanto, os autores notam uma tendência no país à prática de um existencialismo descomprometido com a reflexão sistemática ou pesquisa psicológica, exemplificado por várias propostas de vivências e que em nada mantém conexão com a fenomenologia.

Outro tema de ponderação crítica é o caráter quase invariável de fenomenologia existencial assumido nos trabalhos de psicologia no Brasil. Antonio Gomes Penna (1917-2010), em entrevista concedida à psicóloga Elza Dutra (Dutra, 1997), disse que a fenomenologia e a filosofia existencial devem ser sempre separadas. Segundo o psicólogo, a filosofia existencial nunca usou o método fenomenológico como Husserl o concebeu, o que não seria possível, pois o método propõe um descarte total dos aspectos existenciais para se concentrar nos aspectos essenciais do ser, na estrutura essencial da experiência intencional. Para Penna existem duas correntes, a Psicologia Existencial e a Psicologia Fenomenológica.

A associação entre fenomenologia e filosofia existencial talvez ocorra em um sentido histórico, qual seja a da identificação de uma continuidade de reflexão fenomenológica: do estudo dos invariantes intencionais no mundo da vida husserliano para o estudo das estruturas existenciais do $D a$ sein heideggeriano ou a corporeidade de Merleau-Ponty. As diferenças nessa passagem são inúmeras, mas representam, em síntese, uma modificação de lógica na composição do argumento filosófico e, principalmente, de revisão ontológica na concepção de natureza humana.

\section{Pensamento Brasileiro sobre a Clínica Fenomenológico-Existencial}

Três pesquisadores brasileiros se descaram na apresentação de um posicionamento articulado e sistemático com relação à fenomenologia existencial. Foram eles, Daniela Schneider, da Universidade Federal de Santa Catarina, Yolanda Forghieri, da Universidade de São Paulo, e Mauro Amatuzzi, da Pontifícia Universidade Católica de Campinas.

Schneider (2006) realizou uma análise pertinente da direção do pensamento sartreano em direção à clínica psicológica. Conforme a autora, a metodologia compreensiva descrita por Sartre em suas biografias de Jean Genet e Gustav Flaubert auxiliou na definição da primeira etapa terapêutica da chamada Psicanálise Existencial. Nesse momento, o psicoterapeuta deve buscar a elaboração de uma compreensão terapêutica para a alteração rigorosa e consciente do fenômeno psicológico na clínica. No segundo momento da terapia, realiza-se a investigação das variáveis fundamentais na constituição dos impasses psicológicos do paciente. Essa compreensão se estabelece no horizonte da personalidade ou dinâmica psicológica, do modo como um sujeito se entende sujeito em seus sistemas de certeza existencial. Segundo Schneider, o principal objetivo do processo terapêutico sartreano é possibilitar que o paciente assuma a responsabilidade de seu ser e se torne sujeito de sua história. 
Forghieri (2007) descreveu o processo terapêutico a partir da vivência imediata e pré-reflexiva entre terapeuta e cliente, seguido da reflexão de ambos sobre esse encontro. A circularidade entre vivência imediata e reflexividade constitui a evolução compreensiva em torno da situabilidade do cliente. Esses dois momentos básicos são designados como envolvimento existencial e distanciamento reflexivo, e são interpretados pela autora como uma perspectiva psicológicoterapêutica da redução fenomenológica. Nota-se que os termos lógicos da redução, identificados por Forghieri, apontam para uma dimensão existencial da dinâmica terapêutica e, nesse sentido, demarcam uma disposição de abertura ao novo, ao originário.

A redução fenomenológica entendida nos termos da fenomenologia reflexiva de Husserl propõe a lógica da exclusão de interferências para o acesso da evidência pela consciência. Por outro lado, a posição de uma redução por inclusão da pessoalidade do terapeuta parece mais compatível com a perspectiva fenomenológica da terapia contemporânea, tendo sido inaugurada na virada hermenêutica de Heidegger e seus seguidores.

Amatuzzi (1991) concentra-se no fenômeno da fala em terapia, numa perspectiva hermenêutica. O autor destaca três dimensões presentes na fala: o significado, o sentido e o sinal. A dimensão do significado diz respeito ao conteúdo do que é dito, circunscrito a um contexto e horizonte de enunciação. A dimensão do sentido é o fluxo da interlocução e os intervalos entre vocalização e silêncio. A dimensão do sinal é a indicação de expressão não contida na enunciação. $\mathrm{Na}$ transição da primeira para a segunda dimensão, o significado se amplia para o sentido ao se considerar o fluxo de uma interlocução. O silêncio é aqui considerado também como uma forma de vocalização, desde que o vazio é palco do fluxo da interlocução. Do mesmo modo, a enunciação da palavra silencia outras formas possíveis de comunicação do vivido. Esse entendimento triádico do movimento discursivo na interação terapêutica, como entendida por Amatuzzi (1991), mantém afinidade com a ideia de visibilidade e invisibilidade descrita por Merleau-Ponty (1964/2000), e mesmo com o entendimento de direcionalidade prelinguística à expressão, indicada por Heidegger (1927/1989).

A questão que Amatuzzi (1991) levanta é a da função da fala na terapia. Uma resposta possível seria considerá-la exatamente em sua especificidade expressiva, pois o esforço de traduzir a experiência a um nível comunicativo levaria o sujeito, em última instância, a um reencontro com sua fonte perceptiva. Dessa forma, o raciocínio alinha-se com MerleauPonty (1945/1999) quanto à impossibilidade de se separar percepção de expressão. São ambos processos fincados na experiência do mundo.

As publicações nacionais que abordam a intersecção entre fenomenologia e clínica seguem a tendência internacional de se ocuparem primordialmente dos fundamentos da filosofia fenomenológica e existencial. Tal evidência pode indicar tanto uma preocupação com o domínio do argumento, quanto o revigoramento de um passado epistemológico comum. De acordo com esse segundo sentido, Lima (2008) empreende uma revisão histórica que informa traços de semelhança na origem das psicoterapias fenomenológico-existenciais. De modo semelhante, Moreira (2009) indaga sobre a pertença ou não da Gestalt-Terapia e da Abordagem Centrada na Pessoa a um grande enfoque fenomenológico na psicologia. A autora apontou traços comuns em torno da fenomenologia, mas também aspectos recolhidos de outras tradições, como foi o caso do funcionalismo para a Abordagem Centrada na Pessoa. Até mesmo a aparentemente distante psicologia analítica de Carl Gustav Jung tem sido rediscutida a luz da fenomenologia filosófica (Lima \& Diogo, 2009).

A relação entre fenomenologia e clínica é também foco de debate em contextos diferentes dos que compõem a configuração clássica de atenção terapêutica. Barros e Holanda (2007) relatam que a realização de um evento clínico demanda, por principio, o encontro compreensivo entre duas subjetividades, sendo o gradiente temporal desse encontro fator independente da efetividade do mesmo. Os autores sugerem a modalidade de aconselhamento psicológico como ampliação das possibilidades da clínica psicológica, tal como sugere Forghieri (2007) com o nome de aconselhamento terapêutico. Outra experiência é a do plantão psicológico com referencial fenomenológico (Dutra, 2004, 2008), em que se destaca a inclusão da dimensão social no contexto clínico para a reelaboração da ética de escuta terapêutica.

Especificamente na composição do trabalho clínico, Alvim e Ribeiro (2009) defendem a promoção da ação criativa produtora de significados como veículo de expressão na clínica da Gestalt-Terapia. A ação criativa como experiment-ação clínica, invenção para além do que está dado. Do mesmo modo, Müller-Granzotto e MüllerGranzotto (2007) propõem uma leitura fenomenológica da clínica gestáltica, traçando paralelos entre o emprego da noção de intencionalidade e o emprego gestáltico da noção de awareness. Para os autores, tal como a intencionalidade husserliana se distingue entre processo operante e intencionalidade ato, a awareness se distingue entre sensomotora e reflexiva ou consciente. A diferença entre os dois níveis significa apenas a orientação retrospectiva ou prospectiva da fluidez de experiência. A awareness seria, portanto, um sistema intencional. Além disso, eles falam de uma interpretação fenomenológica das dinâmicas do self, onde selfé entendido como processo temporal de contatos no presente transiente de um indivíduo.

Esses estudos mostram que o debate está ativo na psicologia brasileira. O interesse pelo tema, todavia, não é novidade, como se pode observar na revisão de Gomes, Holanda e Gauer (2004), especialmente em relação às origens da psicologia humanista no país.

\section{Temas Fenomenológicos em Psicologia: Teoria e Pesquisa}

O primeiro registro da revista Psicologia: Teoria e Pesquisa a abordar o tema da fenomenologia é um estudo de caso sobre esquizofrenia (Moreira, 1987). No texto, a autora estabelece aportes à noção fenomenológica de intersubjetividade como eixo de interpretação em um tratamento orientado pela Abordagem Centrada na Pessoa. Em 1988, Gomes, Rech e Ganzo empreendem uma investigação sobre a experiência retrospectiva de estar em psicoterapia, estudo 
que teve seu seguimento publicado na mesma revista dois anos depois (Gomes, 1990). A fenomenologia é aí acessada como método de obtenção e análise hermenêutica dos relatos de pacientes psicoterápicos atendidos por diferentes abordagens psicológicas.

Em 1989, a revista publicou um estudo sobre o conceito de resistência na psicoterapia grupo-analítica do psicanalista Siegmund Foulkes (Ribeiro, 1989). O artigo indica uma aproximação da modalidade grupo-analítica com traços de psicoterapias fenomenológico-existenciais. Segundo o autor, os traços que configuram uma abordagem fenomenológico-existencial são as reversões entre foco e contexto no autorrelato do paciente, o aqui e agora do que acontece na sessão e o sentido novo e operacional do foco sobre o agora. Para Ribeiro, tais traços caracterizariam uma prática analítica da interpretação do presente.

Em 1991, mais uma pesquisa sobre o processo terapêutico é publicada no periódico da UnB. Dessa vez, um estudo de caso coletivo com cinco terapeutas busca acessar, por meio de grupos de supervisão, os conjuntos de perguntas que configuram a experiência do terapeuta na reflexão sobre os casos clínicos (Amatuzzi, Solymos, Ando, Bruscagin \& Costabili, 1991). Referenciando a fenomenologia como método, a análise das supervisões culmina com um conjunto de quatro perguntas sobre a experiência dos terapeutas. As perguntas são as seguintes: (1) que sentido teve para mim esta sessão; (2) o que, em suma, o cliente veio dizer hoje; (3) o que senti durante o atendimento; e (4) o que trocamos neste encontro.

Entre os anos de 1992 e o início de 2002 não foi encontrada publicação na revista associando psicologia à fenomenologia. Em 2002, Rigotto e Gomes analisaram 11 relatos de experiência sobre a abstinência e recaída em dependentes químicos. A análise das entrevistas buscou os invariantes temáticos nos contextos experienciais dos depoentes, algo como uma redução eidética da fala dos participantes. Em 2007, um texto teórico endereça novamente o tema da resistência na clínica, descrevendo os mecanismos de defesa tradicionalmente identificados como resistência na psicanálise para uma releitura fenomenológica do processo (Ribeiro, 2007). Trata-se de uma revisão do artigo original publicado em 1989 na revista.

No ano de 2008, Espinha e Amatuzzi publicam um estudo fenomenológico sobre a vivência de internação em uma enfermaria de adultos em um hospital geral. No mesmo ano, Gauer e Gomes indicam um sentido distinto para a relação entre fenomenologia e psicologia ao publicar um texto sobre memória autobiográfica, consciência e julgamento. Pautado por um modelo experimental de fenomenologia, o estudo discorre sobre as propriedades cognitivas e a qualidade fenomenal da experiência de recordação. Fenomenologia assume aí uma definição distinta, um sentido descritivo do fenômeno de memória autobiográfica. Recentemente, Jost (2010) apresenta um estudo sobre as motivações do adolescente em conflito com a lei. $\mathrm{O}$ trabalho foi baseado em entrevistas individuais com adolescentes privados de liberdade. O objetivo foi articular os núcleos temáticos, formulados a partir de análise fenomenológica hermenêutica dos relatos, com as motivações subjacentes dos adolescentes.

\section{Clínica Fenomenológica: As Evidências}

Conforme a literatura apresentada, os tratamentos psicológicos com base fenomenológico-existential estão presentes nos vários continentes, organizados em sociedades, publicação de livros e periódicos e clínicas de formação. Destaque-se a revista britânica Existential Analysis - Society for Existential Analysis, , em circulação desde 1990. Desse ponto de vista, a clínica fenomenológica continua bem representada no concorrido mundo das psicoterapias.

A grande fragilidade está com relação à pesquisa empírica e a estudos criteriosos da eficiência desses tratamentos. Com efeito, a palavra eficiência não parece ser bem recebida na tradição existencial, certamente por suas restrições às tecnicalidades e às competições inoportunas que afastam o humano da sua condição reflexiva mais profunda. Mendelowitz e Schneider (2008) reconheceram a dificuldade da psicoterapia existencial com a pesquisa, mesmo lembrando que a abordagem nasceu com os estudos de casos. Para os autores, terapeutas existenciais são intelectuais, artistas, poetas, ou filósofos sem maiores vocações para o levantamento empírico, mas que aprendem muito com a arte, com a filosofia e com os pacientes. Para os autores, há dificuldades operacionais em planejar pesquisas longitudinais capazes de acompanhar, com profundidade, o processo terapêutico, e também de financiamento para pesquisa. Mesmo receptivos às pesquisas qualitativas fenomenológicas, o número de estudos empíricos é limitado. Contudo, eles reconheceram que algum progresso em pesquisa vem sendo realizado e os resultados são animadores.

Elliott (2002) conduziu uma meta-análise com estudos sobre os resultados de terapias humanistas e experienciais. Aproximadamente 100 grupos de tratamento foram analisados, incorporando pesquisas com uma ampla variedade de delineamentos metodológicos. As principais conclusões da análise são apresentadas a seguir. A média dos efeitos de mudança produzidos por terapias humanístico-experienciais foram consideradas robustas. Os ganhos pós-terapia foram considerados estáveis, o que significa que são mantidos por até 12 meses até o primeiro follow-up. Em amostras clínicas randomizadas, em comparação com grupos controle que não receberam tratamento, clientes de terapia humanísticoexperiencial obtiveram maior número de mudanças do que os grupos controle. Em amostras clínicas randomizadas, clientes dessa modalidade terapêutica mostraram quantidade equivalente de mudanças em relação a clientes de terapias não humanistas, incluindo tratamentos cognitivo-comportamentais. O tipo de problema apresentado por um paciente, o setting, e o nível de experiência de um terapeuta não afetam o resultado de uma terapia. Por outro lado, a modalidade de tratamento (e.g., casal, terapia de grupo), a fidelidade teórica da pesquisa clínica e o tipo de terapia humanístico-experiencial (modalidades diretivas apresentam efeitos mais longos) interferem no resultado do processo. As terapias de processo diretivo são ligeiramente superiores em relação ao resultado do que terapias cognitivo-comportamentais, mas essas diferenças desaparecem se controlada a fidelidade teórica da pesquisa.

Esses resultados apontam para a efetividade das modalidades terapêuticas humanistas e existenciais. Schneider e Krug (2010) avaliam que os estudos sobre efetividade 
terapêutica passaram por mudanças importantes nos últimos anos, como por exemplo a valorização de fatores contextuais, antes não incluídos, na definição dos critérios de efetividade. Nesse panorama, as psicoterapias de base existencial e humanista passaram a ganhar respeito, especialmente pelo acúmulo recente considerável de suporte empírico em suas práticas. Todavia, como recorda Lantz (2004), até pouco tempo atrás essa modalidade de psicoterapia mantinha sérias restrições ao uso de métodos de pesquisa sistematizados para o estudo da efetividade dos tratamentos. Pesquisas qualitativas, como a história de vida e a grounded theory, ajudaram a desestigmatizar o campo de investigações.

$\mathrm{O}$ interesse por pesquisa em psicoterapia existencial também cresce no Reino Unido, conforme informou Deurzen (2007). A autora, que é diretora da Bristish School of Existential Analysis and Psychotherapy, mencionou um conjunto de iniciativas para formação de terapeutas existenciais junto a universidades e também para a condução de projetos de pesquisa sobre a efetividade da terapia.

Outra tendência promissora é a preocupação de terapeutas existenciais com a cooperação e integração com outras modalidades de tratamento. Tal atitude não nos parece surpreendente, pois Frankl (1946/1973), um dos primeiros terapeutas identificados com existencialismo, utilizava técnicas, como a intenção paradoxal, descrita em 1939, na qual propunha que o paciente exagerasse a sua relação com o sintoma.

Nessa mesma direção, Moss (1989) identificou similaridades entre as psicoterapias fenomenológico-existenciais e as abordagens cognitivo-comportamentais. De acordo com o autor, a psiquiatria fenomenológica foi pioneira em demonstrar, nas décadas de 1920 e 1930, a importância da especificidade linguística, interpretativa e perceptiva nos distúrbios psiquiátricos. No entanto, desde meados da década de 1980, as abordagens cognitivo-comportamentais também demonstram interesse na investigação da linguagem e da cognição na experiência terapêutica. Especialmente, a teoria da autoeficácia, do psicólogo Albert Bandura, aproximou interesses cognitivos, como a antecipação da atribuição de nomes e aprendizagem, com a relevância fenomenológica de significação e atribuição de sentido. Em contraste, técnicas cognitivo-comportamentais são reconhecidas como úteis no auxílio à organização da vida diária dos pacientes e a modos de lidar com depressão.

\section{Considerações Finais}

A problemática que se coloca diante de uma revisão, ao mesmo tempo histórica e contemporânea, é a maneira justa de organizar a agenda temática. Os autores esperam ter atendido a esse compromisso ético. Com efeito, a orientação desse grande e diversificado segmento teórico da psicologia e da psiquiatria tem sido marcada por fidelidade a um passado que exerceu profunda influência no pensamento do século XX, mesmo considerando as suas mais diversas procedências. Nos primórdios, a fenomenologia serviu de apoio metodológico para o afastamento da teoria, mas não da técnica psicanalítica. A estrutura da psicoterapia se manteve muito próxima da psicanálise. No entanto, a regra da interpretação foi modificada, colocando no centro as considerações sobre a existência. Nota-se, na descrição sequencial do processo psicoterapêutico (Binswanger, 1958; Deurzen, 2007; May, 1958; Moss, 1989), um gradativo afastamento da fenomenologia. A fenomenologia como método praticamente desaparece, mesmo em pesquisa. Em contraste, autores brasileiros como Forghieri (2007) e Amatuzzi (1991) mantiveram-se consistentes com a filosofia e o método fenomenológico, com uma proposição teórica processual esclarecida e elegante. A análise de Penna (Dutra, 1997) da distinção entre teorias fenomenológicas e existenciais é procedente. Contudo, o trabalho de Forghieri sugere, sem dúvida, uma efetiva clínica fenomenológica. É uma teoria que merece maiores considerações e estudo.

As posições da literatura sobre a pesquisa empírica nos pareceram controversas, senão ambivalentes. Por um lado, resiste-se à pesquisa; por outro, admite-se que a pesquisa é necessária (Mendelowitz \& Schneider, 2008). Recentemente, destacou-se a importância da cautela dos terapeutas existenciais quanto à corrida por evidências como apoio à psicoterapia (Schneider \& Krug, 2010). Tal fato impressiona, pois, nas últimas décadas do século $\mathrm{XX}$, as pesquisas qualitativas e fenomenológicas se consolidaram no cenário científico. Essas são utilizadas em larga escala nas mais diferentes disciplinas e áreas de especialização e produzem excelentes resultados quando combinadas com métodos quantitativos. No entanto, a questão está sendo tratada com atenção e espera-se que esse esforço venha a ser reconhecido na área (Elliott, 2002).

Nos últimos anos, tem se discutido as possibilidades para integrar noções teóricas e a utilização de técnicas de diferentes procedências em tratamentos psicológicos (Norcross \& Goldfried, 2005). Nesse sentido, e representando uma perspectiva humanístico-existencial, Schneider (2007) incentiva o debate sobre integração com psicoterapias cognitivas de curta duração, com tratamentos para dependentes químicos, e com atendimentos às diversidades diagnósticas e multiculturais. É sem dúvida uma abertura promissora e esperançosa.

Os interesses teóricos alternam-se ou modificam-se ao longo dos anos, e novas ideias estão aí para renovar as nossas metáforas do mundo. No entanto, recebendo ou não nossa atenção, os temas existenciais estarão sempre presentes em nossas vidas e no mundo que nos cerca. Por outro lado, a fenomenologia é, até o presente, o mais rigoroso e efetivo método para conduzir nossas reflexões sobre o conhecimento, sobre a existência e sobre o mundo.

\section{Referências}

Alvim, M. B., \& Ribeiro, J. P. (2009). O lugar da experimentação no trabalho clínico em Gestalt-terapia. Estudos e Pesquisas em Psicologia (UERJ), 9, 37-58.

Amatuzzi, M. M. (1991). Psicoterapia como hermenêutica existencial. Estudos de Psicologia (Campinas), 8, 94-106.

Amatuzzi, M. M., Solymos, G. M. B., Ando, C., Bruscagin, C. B. S., \& Costabili, C. (1991). O sentido-que-faz-sentido: uma pesquisa fenomenológica no processo terapêutico. Psicologia: Teoria e Pesquisa, 7, 1-12. 
Barros, F., \& Holanda, A. (2007). O aconselhamento psicológico e as possibilidades de uma (nova) clínica psicológica. Revista da Abordagem Gestáltica, 13, 75-95.

Binswanger, L. (1958). The existential analysis school of thought. Em R. May, E. Angel \& H. F., Ellenberg (Orgs.), Existence: A new dimension in psychiatry and psychology (pp. 191-213). New York: Simon \& Schuster.

Boss, M. (1958). The analysis of dreams (A. J. Pomerans, Trad.). New York: Philosophical Library. (Trabalho original publicado em 1953)

Breuer, J., \& Freud, S. (1987). Estudos sobre a histeria. Em J. Strackey (Org.), Edição standard brasileira das obras completas de Sigmund Freud, Vol II (pp. 381-511).Rio de Janeiro: Imago. (Trabalho original publicado em 1895)

Campos, N. (1930). Psicologia da vida afetiva. Rio de Janeiro: Fundação Graffé-Guinle.

Campos, N. (1951). O método fenomenológico na psicologia. Rio de Janeiro: s/ editora.

Campos, P. (2007). Phainomenon e lógos na apropriação da fenomenologia de Heidegger. Revista Ética e Filosofia Politica, 10, 1-11.

Casey, E. S. (1977). Imagination and phenomenological method. Em F. Elliston \& P. McCormick (Eds.), Husserl: Expositions and appraisals (pp. 70-82). London: Notre Dame.

Cooper, M. (2009). The inter-experiential field: Perceptions and metaperceptions in person-centered and experiential psychotherapy. Journal of Humanistic Psychology, 49, 85-99.

Deurzen, E. van (2007). What is existencial psychotherapy? Em W. Dryden (Ed.), Dryden's handbook of individual therapy (pp. 195-226). London: Sage.

Deurzen-Smith, E. van (1997). Everyday mysteries: Existential dimensions of psychotherapy. London: Routledge.

Dutra, E. (1997). Entrevista: Antonio Gomes Penna. Estudos de Psicologia, 2, 109-134.

Dutra, E. (2004). Considerações sobre as significações da psicologia clínica na contemporaneidade. Estudos de Psicologia, 9, 381-387.

Dutra, E. (2008). Afinal, o que significa o social nas práticas clínicas fenomenológico-existenciais? Estudos e Pesquisas em Psicologia (UERJ), 8, 224-237.

Elliott, R. (2002). The effectiveness of humanistic therapies: A meta-analysis. Em D. J. Cain \& J. Seeman (Eds.), Humanistic psychotherapies: Handbook of research and practice (pp. 57-81). Washington, DC: APA.

Elliott, B., Joyce, E., \& Shorvon, S. (2009). Delusions, illusions and hallucinations in epilepsy: 1. Elementary phenomena. Epilepsy Research, 85, 162-171.

Espinha, T. G., \& Amatuzzi, M. M. (2008). O cuidado e as vivências de internação em um hospital geral. Psicologia: Teoria e Pesquisa, 24, 477-485.

Farías, V. (1989). Heidegger and nazism. Philadelphia: Temple University Press.

Ferraz, M. S. A. (2004). Lições do mundo-da-vida: o último Husserl e a crítica ao objetivismo. Scientiae Studia, 2, 355-372.

Forghieri, Y. C. (1993). Psicologia fenomenológica: fundamentos, métodos e pesquisa. São Paulo: Pioneira.

Forghieri, Y.C. (2007). Aconselhamento terapêutico: origens, fundamentos e prática. São Paulo: Thomson Learning.

Frankl, V. E. (1973). Psicoterapia e sentido da vida: fundamentos da logoterapia e análise existencial (A. M. de Castro, Trad.). São Paulo: Quadrante. (Trabalho original publicado em 1946)
Freud, S. (1998). Esboços de psicanálise (J. Salomão, Trad.). Em J. Strachey (Org.), Edição standard brasileira das obras completas de Sigmund Freud, Vol. XXIII (pp. 165-237). Rio de Janeiro: Imago. (Trabalho original publicado em 1938/40)

Gauer, G., \& Gomes, W. (2008). Recordação de eventos pessoais: memória autobiográfica, consciência e julgamento. Psicologia: Teoria e Pesquisa, 24, 507-514.

Gomes, W. (1990). A experiência retrospectiva de estar em psicoterapia: um seguimento. Psicologia: Teoria e Pesquisa, 6, 87-106.

Gomes, W. B. (2007). Distinção entre procedimentos técnico e lógico na análise fenomenológica. Revista da Abordagem Gestáltica, 13, 228-240.

Gomes, W., Holanda, A., \& Gauer, G. (2004). Primórdios da psicologia humanista no Brasil. Em M. Massimi (Org.), História da psicologia no Brasil do Século XX (pp. 87-104). São Paulo: E.P.U.

Gomes, W., Rech, A., \& Ganzo, C. (1988). A experiência retrospectiva de estar em psicoterapia: um estudo empíricofenomenológico. Psicologia: Teoria e Pesquisa, 4, 187-206.

Halling. S., \& Nill, J. D. (1995). A brief history of existentialphenomenological psychiatry and psychotherapy. Journal of Phenomenological Psychology, 26, 1-45.

Hegel, G. W. F. (1997). Fenomenologia do espírito - Parte I (P. Meneses, Trad.). Petrópolis: Vozes. (Trabalho original publicado em 1807)

Heidegger, M. (1989). Ser e tempo - Parte I (M. de Sá Cavalcante, Trad.). Petrópolis: Vozes. (Trabalho original publicado em 1927)

Hilgard, E. R. (1987). Psychology in America: A historical survey. Orlando: Hartcourt, Brace Jovanovich.

Hoffman, L., Yang, M., Kaklauskas, F. J., \& Chan, A. (2009). Existencial psychology east-west. Colorado Springs: University of the Rockies Press.

Huisman, D. (2001). História do existencialismo (M. L. Loureiro, Trad.). Bauru: EDUSC. (Trabalho original publicado em 1997).

Husserl, E. (1968). Phenomenological psychology (C. V. Salomon, Trad.). Em W. Sahakian (Ed.), History of psychology: A source book in systematic psychology (pp. 492-494). Itasca: Peacock. (Trabalho original publicado em 1929)

Husserl, E. (2006). Idéias para uma fenomenologia pura e para uma filosofia fenomenológica (M. Suzuki, Trad.). São Paulo: Idéias \& Letras. (Trabalho original publicado em 1913)

Husserl, E. (2007). Investigações lógicas, Vol II (C. A. Morujão, Trad.). Lisboa: Centro de Filosofia da Universidade de Lisboa. (Trabalho original publicado em 1901)

Ihde, D. (1977). Experimental phenomenology: An introduction. New York: Putnam.

Janet, P. (1865). La crise philosophique: MM. Taine, Renan, Littré, Vacherot. Paris: Germer Baillière, Libraire-Èditeur. Retirado em 02/09/2010, de http:/gallica.bnf.fr/ark:/12148/bpt6k860738. $\mathrm{r}=$ Crise.langPT.

Jaspers, K. (2000). Psicopatologia geral: psicologia compreensiva, explicativa, fenomenologia. São Paulo: Atheneu. (Trabalho original publicado em 1913)

Jost, M. C. (2010). Fenomenologia das motivações do adolescente em conflito com a lei. Psicologia: Teoria e Pesquisa, 26, 99-108.

Kierkegaard, S. (1959). Either/Or (L. M. Swenson \& W. Lowrie, Trad.). Garden City: Anchor. (Trabalho original publicado em 1843) 
Kierkegaard, S. (2008). Temor e tremor (T. Guimarães, Trad.). Rio de Janeiro: Ediouro. (Trabalho original publicado em 1843)

Kockelmans, J. J. (1967). Husserl's phenomenology philosophical in the light of contemporary criticism. Em J. J. Kockelmans (Ed.), Phenomenology (pp. 221-236). Garden City: Anchor Books.

Lalande, A. (1996). Dicionário técnico e crítico da filosofia. São Paulo: Martins Fontes.

Lantz, J. (2004). Research and evaluation issues in existential psychotherapy. Journal of Contemporary Psychotherapy, 34, 331-340.

Lima, A. A., \& Diogo, J. C. K. (2009). Reflexões sobre a afinidade de Jung com a fenomenologia. Revista da Abordagem Gestáltica, 15, 13-20.

Lima, B. F. (2008). Alguns apontamentos sobre a origem das psicoterapias fenomenológico-existenciais. Revista da Abordagem Gestáltica, 14, 28-38.

Lourenço Filho, M. B. (1955). Psicologia no Brasil. Em F. Azevedo (Org.), As ciências no Brasil, Vol II (pp. 263-296). São Paulo: Melhoramentos. (Reimpresso em Arquivos Brasileiros de Psicologia Aplicada, 23, 113-142, 1971)

Löwy, M., \& Sayre, R. (1995). Revolta e melancolia: o romantismo na contramão da modernidade (G. J. F. Teixeira, Trad.). Petrópolis: Vozes. (Trabalho original publicado em 1992)

Luborsky, E. B., O’Reilly-Landry, M., \& Arlow, J. A. (2010). Psychoanalysis. Em R. Corsini \& D. Wedding (Eds.), Current psychotherapies (pp. 15-66). New York: Paperback.

May, R., Angel, E., \& Ellenberg H. F. (Orgs), (1958). Existence: A new dimension in psychiatry and psychology. New York: Simon \& Schuster.

May, R. (1958). Contributions of existential psychotherapy. Em R. May, E. Angel, \& H. F. Ellenberg (Orgs.), Existence: A new dimension in psychiatry and psychology (pp. 37-91). New York: Simon \& Schuster.

Mendelowitz, E., \& Schneider, K. (2008). Existential psychotherapy. Em R. J. Corsini \& D. Wedding (Eds.), Current psychotherapies (pp. 295-327). Belmont: Thomson.

Merleau-Ponty, M. (1999). Fenomenologia da percepção. São Paulo: Martins Fontes. (Trabalho original publicado em 1945)

Merleau-Ponty, M. (2000). O visivel e o invisivel. São Paulo: Perspectiva. (Trabalho original publicado em 1964)

Moreira, V. (1987). O enfoque centrado na pessoa no tratamento de um caso de esquizofrenia. Psicologia: Teoria e Pesquisa, 3, 262-281.

Moreira, V. (2009). A gestalt-terapia e a abordagem centrada na pessoa são enfoques fenomenológicos? Revista da Abordagem Gestáltica, 15, 3-12.

Mosak, H. H., \& Maniacci, M. (2010). Adlerian psychotherapy. Em R. Corsini \& D. Wedding (Eds.), Current psychotherapies (pp. 67-112). New York: Paperback.

Moss, D. (1989). Psychotherapy and human experience. Em R. S. Valle \& S. Halling (Orgs.), Existential-phenomenological perspectives in psychology: Exploring the breadth of human experience (pp. 193-213). New York: Springer.

Müller-Granzotto, M. J., \& Müller-Granzotto, R. L. (2007). Fenomenologia e gestalt-terapia. São Paulo: Summus.
Nietzsche, F. (2004). Reflexões sobre os preconceitos morais (P. C. Souza, Trad.). São Paulo: Companhia das Letras. (Trabalho original publicado em 1881)

Norcross, J. C., \& Goldfried, M. R. (2005). Handbook of psychotherapy integration. New York: Oxford University Press.

Penna, A. G. (1985). Sobre os fundamentos históricos e conceptuais da psicologia existencial: acerca das contribuições de Kierkegaard. Arquivos Brasileiros de Psicologia, 37, 8-15.

Radecki, W. (1933). Tratado de psicología (C. Payssé \& V. Delfino, Trad.). Buenos Aires: Casa Editora Jacobo Peuser.

Ribeiro, J. P. (1989). O conceito de resistência na psicoterapia grupo-analítica: repensando um caminho. Psicologia: Teoria e Pesquisa, 5, 123-135.

Ribeiro, J. P. (2007). A resistência olha a resistência. Psicologia: Teoria e Pesquisa, 23, 73-78.

Rigotto, S. D., \& Gomes, W. B. (2002). Contextos de abstinência e de recaída na recuperação da dependência química. Psicologia: Teoria e Pesquisa, 18, 95-106.

Rodrigues, A. C. T. (2005). Karl Jaspers e a abordagem fenomenológica em psicopatologia. Revista Latinoamericana de Psicopatologia Fundamental, 8, 754-768.

Rohrer, J. D., \& Warren, J. D. (2010). Phenomenology and anatomy of abnormal behaviours in primary progressive aphasia. Journal of the Neurological Sciences, 292, 35-38.

Sartre, J-P. (2005). O ser e o nada: ensaio de ontologia fenomenológica. Petrópolis: Vozes. (Trabalho original publicado em 1943)

Schneider, D. R. (2006). Novas perspectivas para a psicologia clínica a partir das contribuições de J. P. Sartre. Interação em Psicologia, 10, 101-112.

Schneider, K. J. (2007). Existential-integrative psychotherapy: Guideposts to the core of practice. New York: Taylor \& Francis.

Schneider, K., \& Krug, O. (2010). Existential-humanistic therapy (Theories of psychotherapy). Washington, DC: APA.

Silva Neto, N. A. (2004). História da perspectiva fenomenológico-existencial - Parte I. Em M. Massimi (Org.), História da psicologia no Brasil do Século XX (pp. 57-74). São Paulo: E.P.U.

Spiegelberg, H. (1972). Phenomenology in psychotherapy and psychiatry. Evanston: Northwestern University.

Spinelli, E. (2007). Practising existential psychotherapy: The relational world. Los Angeles: Sage.

Tavares, J. P., \& Andrade, C. C. (2009). A escuta fenomenológica comprometida pela ótica religiosa de uma gestalt-terapeuta. Revista da Abordagem Gestáltica, 15, 21-29.

Tonner, P. (2009). The return of the relative: Hamilton, Bergson, Merleau-Ponty and French Phenomenology. Janus Head, 11, 308318.

Valle, R. S., \& Halling, S. (1989). Existential-phenomenological perspectives in psychology. New York: Plenum.

Yalom, I. (1980). Existential psychotherapy. New York: Basic Books. 